\title{
Analysis Of The Sustainability Of Endowment Fund Spending Rates From Domestic And Internationally Diversified Portfolios
}

Carl M. Hubbard, (E-mail: chubbard@trinity.edu), Trinity University

\begin{abstract}
Portfolio success rates do not diminish greatly when spending is increased from 5\% to $7 \%$ in equity-heavy portfolios. Foreign equities increase the sustainability of spending rates in shorter planning periods. Portfolio success rate analyses were completed for hypothetical endowment portfolios of S\&P 500 stocks, MSCI's Developed World x USA Index, and high-grade corporate bonds for planning periods of 1, 5, 10, and 15 years using overlapping samples of quarterly returns from the first quarter of 1970 through the fourth quarter of 2003. A portfolio is considered a success if at the end of the planning period the portfolio's nominal value in Table 1 or deflated value in Table 2 net of spending is equal to or greater than its value at the beginning of the planning period. Higher portfolio success rates suggest greater sustainability of spending rates.
\end{abstract}

\section{INTRODUCTION}

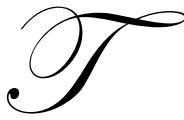

he spending rate and asset allocation are the two issues that are the subjects of ongoing discussion and decisions in the management of institutional endowment funds. In circumstances where current needs are acute, choosing an endowment spending rate is an agonizing tradeoff between future growth of the endowment portfolio and current spending on worthy projects. In making that tradeoff, a key consideration in almost any institution would be the effect of various spending rates on the expected future value of the endowment portfolio in nominal and in real terms.

The asset allocation decision focuses on the proportion of equities versus bonds and also on the allocation of the desired equity proportion among large company U. S. stocks, small company stocks, and foreign stocks. Foreign equity markets have grown in value and technical sophistication and have provided additional diversification of equity holdings. Thus endowment fund managers must take seriously the possible benefits of foreign diversification to determine whether adding foreign stocks increases the sustainability of an institution's spending rate or allows a higher spending rate.

In view of the tradeoff between current spending and future growth and the domestic/foreign equity allocation decision, this research has two objectives: (1) examine the sustainability of various spending rates from portfolios of various stocks/bonds allocation where the overriding objective is to complete finite planning periods with an unimpaired value of the endowment portfolio and (2) examine the impact of foreign equity investments on the sustainability of that same range of spending rates. The metric of sustainability of a spending rate in this analysis is the percentage of hypothetical portfolios that complete planning periods with unimpaired ending values net of planned periodic withdrawals. That percentage is referred to here as the portfolio success rate. The ending portfolio values that are examined to determine success or failure are measured both nominally and in real values. Real ending portfolio values have been deflated to adjust for general price level inflation that occurred during the planning period. 
Following the review of previous research on endowment portfolio spending rates, the data and methodology are described. The results of the spending rate analysis are discussed and reported in the accompanying tables. A summary with concluding comments completes the paper.

\section{PREVIOUS RESEARCH}

Academic research on sustainable spending rates or withdrawal rates from portfolios has focused more on individual retirement portfolios rather than on endowment funds. The few articles on endowment spending tend to recommend specific spending rules or asset allocation policies. For example, Garland (1989) is critical of endowment fund managers who adopt fixed-rate spending policies that tend to be based on total market returns to endowment funds. He recommends a variable spending rate that is equal to the current dividend yield of S\&P 500 stocks.

Dybvig (1999) offers a more complicated solution to the spending rate problem that involves partitioning an endowment fund into two separate portfolios. One would be a portfolio of low-risk fixed-income securities that would provide income for endowment spending. The other portfolio would be invested in riskier assets, such as equities, with higher and more variable returns. In periods of rising equity values gains would be taken from the riskier portfolio and invested in the lower-risk fixed-income portfolio in order to increase cash distributions. Using post-World War II financial market returns, Dybvig found that his strategy would outperform the traditional fixedrate strategy in consistently rising or consistently falling markets but would under perform traditional spending strategies in markets that experienced alternating gains and losses. It appears that the Dybvig strategy would lower portfolio risk and expected return in order to improve the predictability of funds available for endowment spending. Arshanapalli, et al. (2004) offer a similar endowment spending plan that involves the purchase of commercial annuities that would support all disbursements from the endowment fund. The remainder of the fund would be invested in a portfolio of diversified common stocks.

Jones and Wilson (1999) criticize the common 5\% spending rule for endowment funds by showing the number of years from 1926 through 1997 in which such a policy would reduce the end-of-period value of either a $60 \%$ stock $/ 40 \%$ bond endowment fund or a $100 \%$ stock fund below the fund's original value. The authors cite the historical inflation-adjusted returns to the S\&P 500 Index and high-grade corporate bonds and conclude that portfolios with the usual mix of common stocks and bonds could not survive a 5\% annual spending rate in the long run. Jones and Wilson recommend that the question of spending rates be re-examined for shorter planning periods such as five years.

Thaler and Williamson (1994) address asset allocation and recommend that endowment funds allocate greater percentages of funds to equities to enhance the values of funds and increase potential spending. They compared the annual values of a $100 \%$ stock portfolio to annual values of the traditional $60 \%$ stock and $40 \%$ bond portfolio. The authors conclude that from the late 1970's to the early 1990's a 100\% equity endowment fund would have sustained a higher market value in every quarter from the 3rd quarter of 1980 through 3rd quarter of 1993 than the traditional $60 \%$ stock $/ 40 \%$ bond asset allocation.

Pye $(1999,2000)$ provides interesting examples of Monte Carlo simulation in evaluating the long-term sustainability of spending from portfolios. He assumes mean annual real portfolio returns of $6 \%$ to $8 \%$ and standard deviations of returns of $15.9 \%$ to $18 \%$ in log-normal distributions. If future real portfolio returns are $8 \%$ with a standard deviation of $18 \%$, Pye concludes that a $4 \%$ spending rate is highly sustainable over a 35 -year period. He also concludes that lower initial withdrawals from a portfolio reduce the chance of a shortfall in the future. In the case of fixed pension income from a defined benefit retirement plan, real income can be sustained if $26 \%$ to $40 \%$ of the fixed payment is reinvested. Pye's rather conservative conclusions are intuitive and consistent with the literature in this topic that assumes high risk aversion.

With regard to international diversification and portfolio management, Cooley, et al. (2003) concluded that EAFE stocks provided only modest, if any, increase in the sustainability of withdrawal rates from retirement portfolios. The portfolio success rate methodology was applied for planning periods of 15, 20, 25, and 30 years. 
This result is consistent with the higher return and lower variance of returns of S\&P 500 stocks for the sample period in comparison to the EAFE Index.

\section{DATA AND METHODOLOGY}

\section{Data}

The historical financial market returns that are used in this analysis are quarterly total returns to the S\&P 500 Index, quarterly total returns to Morgan Stanley Capital, Inc.'s (MSCI) Developed World x USA Index in U. S. dollars, and quarterly total returns to high-grade U. S. corporate bonds. MSCI's Developed World x USA is their EAFE Index plus Canada. All quarterly returns were derived from the monthly total returns for the three securities from January 1970 through December 2003. S\&P 500 returns and bond returns are reported by Ibbotson Associates (2004), and the MSCI Developed World x USA Index is available on the MSCI website. The sample returns are limited by the December 1969 beginning date of MSCI's foreign equity indexes on their website. Quarterly portfolio returns are weighted averages of quarterly stock and bond returns where the weights are determined by the desired asset allocations.

Portfolio success rates were calculated using U. S. equities only as the equity component of the hypothetical portfolios and alternatively where the equity component of the portfolios was comprised of $72 \% \mathrm{~S} \& \mathrm{P}$ 500 returns and 28\% MSCI Developed World x USA returns. The weights of 0.72 on the S\&P 500 Index and 0.28 on the Developed World x USA Index were calculated by maximizing the Sharpe ratio for a two-asset portfolio of the two equity indexes using 1970 through 2003 quarterly returns. The optimal percentage of the foreign stock index in that context was 28 percent. Calculating portfolio success rates without foreign equities and then with foreign equities allows a straight-forward observation of the effect of foreign equities on the sustainability of spending rates. Quarterly rebalancing of the portfolio to the desired asset allocation is assumed throughout all planning periods.

In the inflation-adjusted analysis portfolio values at the end of planning periods were deflated using relative price indexes that were calculated from quarterly values of the Consumer Price Index - All Urban Consumers (CPIU) as reported by the U. S. Department of Labor, Bureau of Labor Statistics. Gift flows are excluded from this analysis, and the only additions to portfolios are retained or unspent total returns. Spending includes all withdrawals from the endowment fund including management fees and transaction costs.

\section{Methodology}

The overlapping periods methodology that is applied in this analysis calculates quarterly and end-ofplanning-period portfolio values using the financial market returns that are defined above. In order to maximize the use of the comparatively few years of returns, the sample planning periods are advanced by one quarter in the returns data after the completion of an n-year planning period. For example, the ending portfolio value for the first 5 -year planning period is calculated from quarterly returns less spending from the first quarter of 1970 through the fourth quarter of 1974. The ending portfolio value for the second 5-year planning period is calculated from quarterly returns less spending from the second quarter of 1970 through the first quarter of 1975, and so forth.

Reusing sample returns as the overlapping periods methodology suffers from the disadvantage of overuse of returns in the middle years of the available data. Thus the success rate results for longer planning periods may be biased by the financial market returns in those middle years. Also, because the sample planning periods overlap, the end-of-planning-period portfolio values are not independent observations and do not satisfy the independence assumption that may be required for statistical analysis. Consequently the success rates are reported without additional statistical analysis.

Quarterly spending from hypothetical portfolios is determined by specified spending rates and trailing 12quarter average values of the portfolios. Multiplying a fixed spending rate times a trailing moving average of portfolio values is a common approach for calculating spending from endowment funds. According to the 1999 
NACUBO Endowment Study (2000), 345 of the 473 reporting institutions spend a pre-specified percentage of a moving average of the market values of their endowment funds. Calculating spending from a moving average value of a portfolio serves to reduce the variation in annual spending relative to quarterly variations in portfolio returns and values. The practice of calculating a moving average portfolio value as of the previous year's end date also provides a predetermined amount of endowment spending for the budget year. At the conclusion of four quarters, the 12-quarter moving average method requires that the earliest four quarters of portfolio values in the moving average calculation be dropped and the latest four quarters added to form a new 12-quarter sample for a recalculation of a new 12-quarter average portfolio value. That new moving average and the spending rate determine the subsequent year's endowment spending.

The equation for the calculation of an end-of-quarter value of a portfolio is the following:

$\mathrm{V}_{\mathrm{t}}=\mathrm{V}_{\mathrm{t}-1}\left(1+\mathrm{r}_{\mathrm{t}}\right)-\mathrm{s}_{\mathrm{ttq}}$

in which

$\mathrm{V}_{\mathrm{t}}=$ end of quarter market value of the portfolio

$\mathrm{V}_{\mathrm{t}-1}=$ market value of the portfolio at the beginning of the quarter;

$\mathrm{r}_{\mathrm{t}}=$ total return to the portfolio for that quarter;

$\mathrm{s} \quad=\quad$ pre-specified spending rate; and

$\mathrm{V}_{\mathrm{ttq}} \quad=\mathrm{t} \quad$ railing 12-quarter average value of the portfolio.

Since portfolio success is judged by $\mathrm{V}_{\mathrm{t}}$ at the conclusion of a planning period, a portfolio is considered a success if $\mathrm{V}_{\mathrm{t}}$ at the end of the planning period is equal to or greater than $\mathrm{V}_{0}$, the value of the portfolio at the beginning of a planning period. In the cases where success is judged by the ending real or deflated value of the portfolio, a portfolio is considered a success if the CPI deflated value of $\mathrm{V}_{\mathrm{t}}$ at the end of a planning period is equal to or greater than $\mathrm{V}_{0}$. That is, if the following equation is true for a portfolio at the end of a planning period, the portfolio is considered a success:

$\mathrm{V}_{\mathrm{n}} \geq \mathrm{V}_{0}$

for the nominal value comparison and

$\mathrm{V}_{\mathrm{n}}\left(\mathrm{CPI}-\mathrm{U}_{0} / \mathrm{CPI}-\mathrm{U}_{\mathrm{n}}\right) \geq \mathrm{V}_{0}$

for the real value comparison in which $\mathrm{V}_{\mathrm{n}}=$ nominal value of a portfolio at the end of a planning period, $\mathrm{CPI}-\mathrm{U}_{0}=$ consumer price index for urban consumers at the beginning of a planning period, and $\mathrm{CPI}-\mathrm{U}_{\mathrm{n}}=$ consumer price index for urban consumers at the end of a planning period. The calculation of $\mathrm{V}_{\mathrm{t}}$ through planning periods is repeated using overlapping samples of quarterly returns for the 1, 5, 10, and 15-year planning periods. The percentage of portfolios of a particular asset allocation and spending rate that complete a planning period with unimpaired ending real values as defined in Equations (2) and (3) represents a portfolio success rate. The success rate analysis is repeated until the analysis is complete for all spending rates and asset allocations that are considered in the research.

The initial 12 quarters starting with the first quarter of 1970 pose a unique problem. Because those quarters do not have 12 quarters of history for the calculation of 12-quarter trailing average portfolio values, the spending amounts in the initial 12 quarters are unavoidable exceptions to the 12-quarter moving average formula that would require a disproportionate weighting of the initial $\$ 1,000$ portfolio value until the calculation process completes the first 12 quarters. Therefore, in order to report results from consistently applied methodology, the portfolio success rate analyses begin with the first quarter of 1973.

Beginning with the first quarter of 1973, the portfolio success rates were calculated from 121 overlapping 1-year portfolios, 1055 -year portfolios, 85 10-year portfolios, and 6515 -year portfolios. The annualized spending 
rates tested in the analysis ranged from $3.0 \%$ to $8.0 \%$ incremented by 1.0 percent. The portfolio allocations of $100 \%$ large company stock, $80 \%$ stock $-20 \%$ corporate bonds, $60 \%$ stock $-40 \%$ bonds, $50 \%$ stock $-50 \%$ bonds, and $40 \%$ stock $-60 \%$ bonds are examined in the analysis. As discussed above, equity in the first analysis consists entirely of S\&P 500 Index returns, but the second set of analyses includes both S\&P 500 returns and Developed World x USA returns.

\section{RESULTS}

Table 1 reports the percentages of portfolios that completed planning periods with ending nominal values net of spending that were equal to or greater than the beginning values of those portfolios. The nominal value analysis is important to institutions that must avoid reducing or borrowing any portion of the book value of their endowment funds. For example, university accreditation agencies require that such borrowing to be accounted for as the institution would account for a loan from a bank.

As previously discussed, the success rate analysis that is reported in Table 1 begins with the 1 st quarter of 1973 and ends with the fourth quarter of 2003. The columns in Table 1 under "Annualized Spending Rate" list the portfolio success rates by spending rate, planning period, and portfolio allocation. As expected, the success rates decline as spending rates increase from $0 \%$ to $8 \%$ but the decline is not as great as one might expect. Success rates are somewhat higher for 1-year and 5-year planning periods in portfolios with greater allocations of common stock. In longer planning periods of 10 years and 15 years the success rates tend to be close to $100 \%$ for all spending rates and for all asset allocations. International equity diversification added as much as $4 \%$ to some portfolio success rates. At the standard 5.0\% spending rate $88 \%$ of the domestic (U. S.) $60 \%$ stocks $/ 40 \%$ bonds portfolios (60/40) successfully completed 5-year planning periods with no loss of nominal value. With foreign equity diversification, that success rate increased by $3 \%$ to $91 \%$. With foreign equities the portfolio success rates net of $6 \%$ spending from the $60 / 40$ bonds portfolios are about the same as the 5\% spending success rate with domestic portfolios. The success rates in Table 1 suggest that international equity diversification increases the sustainability of spending rates in the shorter 1 year and 5 year planning periods where the portfolio allocations include some bonds.

The increase in success rates with international equity diversification derives from the 0.709 correlation of returns to the Developed World x USA Index with returns to the S\&P 500 Index. Also the correlation of the Developed World $x$ USA Index with returns to U. S. corporate bonds is 0.231 which is lower than the S\&P $500 /$ corporate bonds correlation of 0.323 . Thus the stabilizing effect of the international equities increases portfolios success rates. For longer planning periods the somewhat higher returns and lower standard deviation of returns to the S\&P 500 over the sample period diminishes the added value of the foreign equities.

The success rates in Table 1 also facilitate incremental return/risk. For example, when considering increasing spending from an endowment, policy makers could compare expected success rates associated with higher spending rates with the success rate associated with the current, lower spending rate. In the example above with a 5-year planning period, an increase from 5\% spending to $6 \%$ spending has some negative effect on portfolio success rates. In the $60 / 40$ portfolios the success rate drops from $88 \%$ to $86 \%$ for domestic portfolios and $91 \%$ to $87 \%$ for portfolios with foreign equities. Whether the greater risk of reducing the value of the endowment portfolio is justified depends on the additional benefits of the greater amount of current spending in comparison to the risks associated with slower growth.

The figures in Table 1 indicate a spending policy that allows no possible impairment of the value of a portfolio is incompatible with the realities of the financial markets. Recent history teaches us that endowment funds can experience losses of value net of even conservative spending rates. Thus sustainability of a spending rate is a relative concept and should not be judged relative to $100 \%$ portfolio success but rather to success rates that are associated with alternative spending rates.

The portfolio success rates in Table 2 have the same meaning as those in Table 1; however, the standard for success is more rigorous. As shown by Equation (3), in order for a portfolio to be a success, the deflated ending value of that portfolio must be equal to or greater than its beginning value. When sustaining a real ending portfolio 
value is the primary objective in managing an endowment fund, foreign equity diversification appears to lose some of its advantage. The success rates in Table 2 indicate that the inclusion of foreign stocks increases portfolio success rates primarily for 1 year planning periods and for spending rates that are less than $7 \%$. This reduced advantage of foreign equities in the inflation-adjusted analyses may be the result of the somewhat lower average quarterly returns to the MSCI Developed World x USA Index (0.0305) in comparison to S\&P 500 returns (0.0308) and higher standard deviation of quarterly returns $(0.0956$ versus 0.0857$)$.

If the terminal value goal in managing an endowment fund is to maintain real value, the success rates in Table 2 allow managers to compare portfolio success rates for the range of spending rates and asset allocations. As in Table 1 the portfolio success rates do not diminish greatly when the spending rate is increased from $3 \%$ to $6 \%$ in portfolios of at least $60 \%$ equities. Increasing spending from $6 \%$ to $7 \%$ or $8 \%$ causes noticeable reductions in portfolio success rates. Also, greater bond allocations reduce portfolio success rates at spending rates of $4 \%$ or higher. Thus Tables 1 and 2 suggest that spending rates in the $4 \%$ and $5 \%$ range provide about the same portfolio success rates. The reduction in success rates when spending is increased to $6 \%$ is in the range of $1 \%$ to $7 \%$ which may be acceptable to some institutions on a short-term basis.

None of the analysis reported above suggests that higher spending rates should be continued through a bear market when there are alternatives. Although the analyses reported in Tables 1 and 2 are the results of strict spending rules that are not adjusted in bear or bull markets, spending $6 \%$ or even $5 \%$ of an endowment fund in a declining market risks impairing the long-term growth of the endowment portfolio. If the spending rates were adjustable in the 3\% to 7\% range depending on financial market conditions, the portfolio success rates in Tables 1 and 2 associated with that range of spending rates would likely increase materially.

\section{SUMMARY AND CONCLUSIONS}

Portfolio success rates were calculated for hypothetical portfolios of S\&P 500 stocks and high-grade corporate bonds through planning periods of $1,5,10$, and 15 years using overlapping samples of returns from the first quarter of 1970 through the fourth quarter of 2003. A portfolio is considered a success if at the end of the planning period the portfolio's nominal value in Table 1 or deflated value in Table 2 net of spending is equal to or greater than its value at the beginning of the planning period. The conclusions of this study are the following:

1. The implications of the analysis reported in Tables 1 and 2 are largely intuitive - higher portfolio success rates are associated with lower spending rates and greater allocations of common stock, a finding that is consistent with the Thaler and Williamson (1994) thesis that endowment funds benefit from substantial allocations of common stock.

2. Tables 1 and 2 suggest that in shorter planning periods, portfolio success rates as defined in this paper do not diminish greatly when annual spending is increased from $5 \%$ to $7 \%$ in equity-heavy portfolios. However, over planning periods of 10 years or more, portfolio success appears to be quite sensitive to increased spending regardless of the portfolio composition. That finding suggests that maintaining higher spending rates, say $6 \%$ to $7 \%$, is inadvisable for longer planning periods.

3. Foreign equity diversification increases the sustainability of spending rates in shorter planning periods.

4. Since all spending rates, including $0.0 \%$, have some probability of impairing the real value of an endowment fund, the proper evaluation a higher spending rate compares the success rate of the higher spending rate with that of the lower spending rate. Such a comparison focuses the policymaker's attention on the marginal utility of the increase in spending versus the reduced growth of the endowment portfolio.

5. One area of additional research on this topic would be the analysis of portfolio success rates net of adjustable spending rates in bear and bull markets.

\section{REFERENCES}

1. 1999 NACUBO Endowment Study. 2000. Washington, DC: National Association of College and University Business Officers. 
2. Arshanapalli, Bala, Edmond D’Ouville and William Nelson. 2004. "A New Endowment Distribution Plan: How to Insure Current Spending While Growing the Fund Corpus." Journal of Wealth Management, Vol. 6, No. 4 (spring): 24-28.

3. Cooley, Phillip L., Carl M. Hubbard and Daniel T. Walz. 2003. "Does International Diversification Increase the Sustainable Withdrawal Rates from Retirement Portfolios?" Journal of Financial Planning, Vol. 16, No. 1 (January): 74-80.

4. Dybvig, Philip H. 1999. "Using Asset Allocation to Protect Spending." Financial Analysts Journal, vol. 55, no. 1 (January - February): 49-62.

5. Garland, James P. 1989. “A Market-Yield Spending Rule for Endowments and Trusts.” Financial Analysts Journal, vol. 45, no. 4 (July-August): 50-60.

6. Ibbotson Associates. 2004. Stocks, Bonds, Bills, and Inflation 2004 Yearbook. Chicago, IL: Ibbotson Associates.

7. Jones, Charles P. and Jack W. Wilson. 1999. "Expectations About Real Returns." Journal of Portfolio Management, vol. 25, no. 2 (winter): 45-52.

8. Morgan Stanley Capital Inc., Equity Indexes at www.msci.com/

9. Pye, Gordon B. 1999. "Sustainable Real Spending from Pensions and Investments." Journal of Financial Planning, vol. 12, no. 6 (June): 80-91.

10. 2000. "Sustainable Investment Withdrawals." Journal of Portfolio Management, vol. 26, no. 4 (summer): $73-83$.

11. Thaler, Richard H. and J. Peter Williamson. 1994. "College and University Endowment Funds: Why Not 100\% Equities?” Journal of Portfolio Management, vol. 21, no. 1 (fall): 27-37.

12. U. S. Department of Labor, Bureau of Labor Statistics at www.bls.gov/ 
Table 1

Percentage of Portfolios Completing Planning Periods With No Loss of Nominal Value after Quarterly Spending, Domestic U.S. Stocks vs. International Equity Diversitication: 1970 - 2003

\begin{tabular}{|c|c|c|c|c|c|c|c|}
\hline \multirow[b]{2}{*}{ Planning Period } & \multicolumn{7}{|c|}{ Annualized Spending Rate } \\
\hline & $0.0 \%$ & $3.0 \%$ & $4.0 \%$ & $5.0 \%$ & $6.0 \%$ & $7.0 \%$ & $8.0 \%$ \\
\hline & US / Int'l & US / Int'l & US / Int'l & US / Int'l & US / Int'l & US / Int'1 & US / Int'] \\
\hline \multicolumn{8}{|l|}{$100 \%$ Stock } \\
\hline 1 year & $76 / 77$ & $70 / 73$ & $69 / 71$ & $69 / 71$ & $69 / 67$ & $67 / 64$ & $64 / 62$ \\
\hline 5 years & $93 / 95$ & $91 / 91$ & $90 / 90$ & $89 / 90$ & $88 / 89$ & $88 / 89$ & $85 / 85$ \\
\hline 10 years & $100 / 100$ & $100 / 100$ & $100 / 100$ & $100 / 100$ & $100 / 100$ & $99 / 98$ & $98 / 93$ \\
\hline 15 years & $100 / 100$ & $100 / 100$ & $100 / 100$ & $100 / 100$ & $100 / 100$ & $100 / 100$ & $100 / 98$ \\
\hline \multicolumn{8}{|c|}{$80 \%$ Stock, $20 \%$ Bonds } \\
\hline 1 year & $76 / 77$ & $70 / 74$ & $69 / 71$ & $69 / 69$ & $68 / 68$ & $67 / 67$ & $65 / 64$ \\
\hline 5 years & $99 / 99$ & $92 / 92$ & $91 / 91$ & $90 / 90$ & $87 / 90$ & $84 / 88$ & $81 / 84$ \\
\hline 10 years & $100 / 100$ & $100 / 100$ & $100 / 100$ & $100 / 100$ & $100 / 100$ & $99 / 99$ & $98 / 96$ \\
\hline 15 years & $100 / 100$ & $100 / 100$ & $100 / 100$ & $100 / 100$ & $100 / 100$ & $100 / 100$ & $100 / 100$ \\
\hline \multicolumn{8}{|c|}{$60 \%$ Stock, $40 \%$ Bonds } \\
\hline 1 year & $76 / 80$ & $71 / 75$ & $71 / 74$ & $69 / 73$ & $69 / 69$ & $64 / 67$ & $61 / 62$ \\
\hline 5 years & $100 / 100$ & $97 / 98$ & $92 / 93$ & $88 / 91$ & $86 / 87$ & $82 / 84$ & $79 / 80$ \\
\hline 10 years & $100 / 100$ & $100 / 100$ & $100 / 100$ & $100 / 100$ & $100 / 100$ & $99 / 99$ & $96 / 95$ \\
\hline 15 years & $100 / 100$ & $100 / 100$ & $100 / 100$ & $100 / 100$ & $100 / 100$ & $100 / 100$ & $100 / 100$ \\
\hline \multicolumn{8}{|c|}{$50 \%$ Stock, $50 \%$ Bonds } \\
\hline 1 year & $78 / 81$ & $74 / 75$ & $70 / 74$ & $69 / 72$ & $66 / 69$ & $62 / 64$ & $60 / 61$ \\
\hline 5 years & $100 / 100$ & $99 / 99$ & $94 / 97$ & $89 / 90$ & $84 / 87$ & $80 / 82$ & $78 / 79$ \\
\hline 10 years & $100 / 100$ & $100 / 100$ & $100 / 100$ & $100 / 100$ & $100 / 100$ & $99 / 99$ & $95 / 95$ \\
\hline 15 years & $100 / 100$ & $100 / 100$ & $100 / 100$ & $100 / 100$ & $100 / 100$ & $100 / 100$ & $100 / 100$ \\
\hline \multicolumn{8}{|c|}{$40 \%$ Stock, $60 \%$ Bonds } \\
\hline 1 year & $83 / 84$ & $74 / 75$ & $73 / 73$ & $66 / 70$ & $63 / 67$ & $61 / 65$ & $59 / 57$ \\
\hline 5 years & $100 / 100$ & $97 / 99$ & $95 / 96$ & $90 / 92$ & $83 / 85$ & $79 / 81$ & $77 / 77$ \\
\hline 10 years & $100 / 100$ & $100 / 100$ & $100 / 100$ & $100 / 100$ & $100 / 100$ & $98 / 98$ & $93 / 94$ \\
\hline 15 years & $100 / 100$ & $100 / 100$ & $100 / 100$ & $100 / 100$ & $100 / 100$ & $100 / 100$ & $100 / 100$ \\
\hline
\end{tabular}

Note: A portfolio is successful if its value at the end of the planning period is equal to or greater than its value at the beginning of that planning period. Stock returns are total returns to the S\&P 500 in the US portfolios and 72\% S\&P 500 and 28\% MSCI Developed World x USA in Int'l portoflios. Bonds returns are total returns to long-term high-grade corporate bonds. S\&P 500 returns and bond returns are published by Ibbotson Associates. MSCI Developed World x USA equity returns are published at www.msci.com. Quarterly spending amounts are calculated by multiplying the pre-specified annual spending rate divided by 4 times the trailing 3-years' 12-quarter average value of the portfolio. Since the earliest post-war period with returns data are from the first quarter of 1970, the success rate analysis begins with portfolio values as of the end of the first quarter of 1973. 
Table 2

Percentage of Portfolios Completing Planning Periods With No Loss of Real Value after Quarterly Spending, Domestic Stocks vs. International Equity Diversitication: 1970 - 2003

\begin{tabular}{|c|c|c|c|c|c|c|c|}
\hline \multirow[b]{2}{*}{ Planning Period } & \multicolumn{7}{|c|}{ Annualized Spending Rate } \\
\hline & $0.0 \%$ & $3.0 \%$ & $4.0 \%$ & $5.0 \%$ & $6.0 \%$ & $7.0 \%$ & $8.0 \%$ \\
\hline & US / Int'l & US / Int'l & US / Int'l & US / Int'l & US / Int'1 & US / Int'l & US / Int'l \\
\hline \multicolumn{8}{|l|}{$100 \%$ Stock } \\
\hline 1 year & $74 / 77$ & $69 / 72$ & $68 / 70$ & $66 / 70$ & $66 / 69$ & $65 / 64$ & $64 / 63$ \\
\hline 5 years & $84 / 87$ & $78 / 78$ & $78 / 75$ & $75 / 72$ & $70 / 68$ & $69 / 59$ & $63 / 50$ \\
\hline 10 years & $98 / 98$ & $93 / 94$ & $92 / 92$ & $92 / 91$ & $91 / 84$ & $86 / 82$ & $74 / 76$ \\
\hline 15 years & $100 / 100$ & $100 / 100$ & $98 / 100$ & $97 / 98$ & $94 / 94$ & $89 / 85$ & $88 / 80$ \\
\hline \multicolumn{8}{|c|}{$80 \%$ Stock, $20 \%$ Bonds } \\
\hline 1 year & $74 / 78$ & $69 / 73$ & $67 / 71$ & $66 / 69$ & $65 / 67$ & $64 / 67$ & $63 / 64$ \\
\hline 5 years & $81 / 85$ & $76 / 77$ & $75 / 76$ & $73 / 69$ & $69 / 62$ & $61 / 56$ & $59 / 51$ \\
\hline 10 years & $98 / 98$ & $92 / 93$ & $92 / 92$ & $91 / 92$ & $88 / 87$ & $80 / 78$ & $74 / 73$ \\
\hline 15 years & $100 / 100$ & $100 / 100$ & $98 / 100$ & $95 / 98$ & $92 / 95$ & $91 / 89$ & $80 / 78$ \\
\hline \multicolumn{8}{|c|}{$60 \%$ Stock, $40 \%$ Bonds } \\
\hline 1 year & $75 / 80$ & $70 / 75$ & $70 / 73$ & $66 / 70$ & $62 / 67$ & $61 / 61$ & $60 / 60$ \\
\hline 5 years & $85 / 86$ & $76 / 74$ & $72 / 70$ & $68 / 66$ & $65 / 63$ & $62 / 57$ & $58 / 52$ \\
\hline 10 years & $98 / 98$ & $92 / 92$ & $92 / 92$ & $89 / 89$ & $84 / 85$ & $79 / 76$ & $68 / 68$ \\
\hline 15 years & $100 / 100$ & $100 / 100$ & $97 / 100$ & $94 / 97$ & $92 / 94$ & $91 / 89$ & $72 / 71$ \\
\hline \multicolumn{8}{|c|}{$50 \%$ Stock, $50 \%$ Bonds } \\
\hline 1 year & $81 / 81$ & $70 / 76$ & $68 / 74$ & $64 / 69$ & $62 / 65$ & $59 / 60$ & $57 / 55$ \\
\hline 5 years & $85 / 84$ & $72 / 71$ & $70 / 68$ & $67 / 67$ & $65 / 63$ & $62 / 57$ & $54 / 51$ \\
\hline 10 years & $96 / 95$ & $92 / 92$ & $89 / 89$ & $86 / 87$ & $81 / 84$ & $78 / 73$ & $64 / 66$ \\
\hline 15 years & $100 / 100$ & $100 / 100$ & $97 / 100$ & $94 / 97$ & $91 / 94$ & $83 / 88$ & $68 / 58$ \\
\hline \multicolumn{8}{|c|}{$40 \%$ Stock, $60 \%$ Bonds } \\
\hline 1 year & $85 / 86$ & $71 / 73$ & $66 / 69$ & $63 / 67$ & $60 / 64$ & $59 / 57$ & $56 / 53$ \\
\hline 5 years & $83 / 83$ & $73 / 70$ & $69 / 69$ & $67 / 66$ & $65 / 62$ & $61 / 58$ & $55 / 47$ \\
\hline 10 years & $95 / 95$ & $92 / 92$ & $87 / 87$ & $85 / 86$ & $80 / 81$ & $69 / 68$ & $59 / 54$ \\
\hline 15 years & $100 / 100$ & $98 / 100$ & $97 / 98$ & $92 / 94$ & $91 / 92$ & $77 / 80$ & $63 / 54$ \\
\hline
\end{tabular}

Note: A portfolio is successful if its CPU(U) deflated value at the end of the planning period is equal to or greater than the value at the beginning of that planning period. Stock returns are total returns to the S\&P 500 in the US portfolios and 72\% S\&P 500 and 28\% MSCI Developed World x USA in Int'l portoflios. Bonds returns are total returns to long-term high-grade corporate bonds. S\&P 500 returns and bond returns are published by Ibbotson Associates. MSCI Developed World x USA equity returns are published at www.msci.com. The CPI(U) is published by the U. S. Department of Labor at www.bls.com. Quarterly spending amounts are calculated by multiplying the pre-specified annual spending rate divided by 4 times the trailing 3-years' 12-quarter average value of the portfolio. Since the earliest post-war period with returns data are from the first quarter of 1970, the success rate analysis begins with portfolio values as of the end of the first quarter of 1973. 


\section{NOTES}

